\title{
New data on the morphology of some Far-Eastern species of Rhabdochona (Nematoda: Rhabdochonidae), as revealed by SEM observations
}

\author{
František Moravec $^{1}$, Aleksei V. Ermolenko², Vladimir V. Besprozvannykh² and Tomáš Scholz ${ }^{1}$ \\ ${ }^{1}$ Institute of Parasitology, Biology Centre of the Academy of Sciences of the Czech Republic, Branišovská 31, 37005 České \\ Budějovice, Czech Republic; \\ ${ }^{2}$ Institute of Biology and Soil Science, Far Eastern Branch of the Russian Academy of Sciences, 159, Stoletiya Prospekt, 690022, \\ Vladivostok, Russia
}

\begin{abstract}
Specimens of the nematode genus Rhabdochona Railliet, 1916 (Rhabdochonidae) were collected during helminthological examination of four species of cyprinid fishes in two rivers of the Amur River basin in the Russian Far East (Primorsky Region) in June 2011. Detailed light microscopical (LM) and scanning electron microscopical (SEM) examinations (the latter used for the first time for the reported nematode species) of the available material revealed the presence of three inadequately described nominal species of this genus: R. (Rhabdochona) denudata (Dujardin, 1845) from the spotted steed Hemibarbus maculatus Bleeker (Gobioninae), and R. (Rhabdochona) longispicula Belous in Roytman, 1963 and R. (Globochonoides) coronacauda Belous, 1965 from Culter alburnus Basilewsky (Cultrinae) in the Ilistaya River. Detailed morphological study of these worms, especially SEM examination, made it possible to reveal some previously unreported morphological features (e.g., the presence of sublabia or the character of ventral precloacal ridges) and to confirm other taxonomically important characters such as the shape of deirids, number of anterior prostomal teeth, number and situation of lateral preanal and postanal papillae or the detailed structure of the crown-like formation on the female tail tip in R. coronacauda. Unidentifiable Rhabdochona (Rhabdochona) gravid females were recorded from the humpback Chanodichthys dabryi (Bleeker) (Cultrinae) in the Ilistaya River and from the Amur minnow Rhynchocypris lagowskii (Dybowski) (Leuciscinae) in the Komissarovka River.
\end{abstract}

Keywords: parasitic nematodes, Rhabdochona, freshwater fish, Chanodichthys, Culter, Hemibarbus, Russian Far East

At present the nematode genus Rhabdochona Railliet, 1916 includes 95 valid species parasitizing freshwater fishes in all main zoogeographical regions (Moravec et al. 2012a). However, the morphology and the degree of intraspecific variability remain insufficiently known for many species, which complicates the taxonomy and species identification of these widely distributed fish parasites. Moreover, some important taxonomic features in these nematodes can be reliably studied only with the use of scanning electron microscopy (SEM) (Moravec 2007a).

To date, the following seven nominal species of Rhabdochona were reported from the Amur River basin and Primorsky Region, southern Far East of Russia: R. brevispicula Akhmerov, 1965; R. coronacauda Belous, 1965; R. crassa Finogenova, 1967; R. denudata (Dujardin, 1845); R. longispicula Belous in Roytman, 1963; R. oncorhynchi (Fujita, 1921) and R. zacconis Yamaguti, 1935 (see, e.g., Dogel and Akhmerov 1959, Roytman 1963, Roytman and Trofimenko 1964, Belous 1965, Finogenova 1967, 1971, Bauer 1987, Ermolenko 1990, 1992,
Ermolenko and Butorina 1998). However, two of them (R. brevispicula and R. crassa) were subsequently synonymized by Moravec (1975) with $R$. denudata; although this synonymy was accepted in the monograph of Bauer (1987), some authors (Ermolenko 1990, 1992) have considered $R$. crassa a valid species. Unfortunately, the morphology of all the above-mentioned Far-Eastern Rhabdochona spp. remains insufficiently known and none has so far been studied by SEM.

During helminthological examinations of some fishes from the Ilistaya and Komissarovka Rivers (tributaries of Lake Khanka, Amur River basin), Primorsky Region, eastern Russia, carried out in June 2011, adult nematodes of Rhabdochona were recorded from four species of cyprinids. This available material made it possible to identify three nominal Rhabdochona spp., whereas congeneric specimens (only females) from two host species could not be identified to the species level. A detailed study of these nematodes using LM and SEM enabled us to revise taxonomic features and obtain some new mor- 
phological data in the three identified species. Results of this study are presented herein.

\section{MATERIALS AND METHODS}

Of the fishes from the Ilistaya River near Chernigovka $\left(44^{\circ} 26^{\prime} 47^{\prime \prime} \mathrm{N}, 132^{\circ} 25^{\prime} 20^{\prime \prime} \mathrm{E}\right)$ and the Komissarovka River

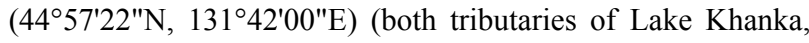
Amur River basin), Primorsky Region, southern Far East of Russia examined in June 2011, the following species harboured Rhabdochona specimens: humpback, Chanodichthys dabryi (Bleeker); Culter alburnus Basilewsky; spotted steed, Hemibarbus maculatus Bleeker; and Amur minnow, Rhynchocypris lagowskii (Dybowski) (all Cyprinidae, Cypriniformes).

Nematodes were fixed in hot $4 \%$ formaldehyde solution and cleared with glycerine for LM examination. Drawings were made with the aid of a Zeiss microscope drawing attachment. Specimens used for SEM were first transferred to $4 \%$ formaldehyde solution; later they were postfixed in $1 \%$ osmium tetroxide (in phosphate buffer), dehydrated through a graded acetone series, critical-point-dried and sputter-coated with gold; they were examined using a JEOL JSM-7401F scanning electron microscope at an accelerating voltage of $4 \mathrm{kV}$ (GB low mode). All measurements are in micrometres unless otherwise indicated. Fish names follow FishBase (Froese and Pauly 2012).

\section{RESULTS}

\section{Family Rhabdochonidae Travassos, Artigas et Pereira, 1928}

Rhabdochona (Rhabdochona) denudata (Dujardin, 1845)

Figs. 1, 2

Syns.: Dispharagus denudatus Dujardin, 1845; Cucullanus pachystomus Linstow, 1873; Dispharagus filiformis Zschokke, 1884; Rhabdochona brevispicula Akhmerov, 1965; R. crassa Finogenova, 1967; R. leucaspii Kritscher, 1979; R. mesopotamica Rahemo et Kasim, 1979.

Description: Medium-sized nematodes with smooth cuticle (Fig. 1A). Oral aperture hexagonal, surrounded by four small submedian cephalic papillae and pair of lateral amphids; four small submedian sublabia present (Figs. 1E, 2A,B). Prostom funnel-shaped, without basal teeth (Fig. 1A-D), lined internally with longitudinal ribs forming anteriorly 14 small forwardly directed teeth (Figs. 1E, 2A,B). Vestibule straight, relatively long (Fig. 1A-D). Medium-sized deirids bifurcate, situated posterior to midlength of vestibule (Figs. 1B-D,H, 2D). Tail of both sexes conical, with sharp cuticular spike at tip (Figs. 1F,G,J,K, 2C,H).

Male (one specimen): Length of body $8.43 \mathrm{~mm}$, maximum width 122 . Length of vestibulum including prostom 147; prostom 27 long, 21 wide. Muscular oesophagus 327 long, maximum width 36 (Fig. 1A); glandular oesophagus $3.37 \mathrm{~mm}$ long, maximum width 75; length ratio of both parts of oesophagus $1: 10$. Entire oesophagus and vestibule representing $46 \%$ of body length. Nerve ring and excretory pore 198 and 288, respectively, from anterior extremity (Fig. 1A,B). Deirids situated 88 from anterior end of body. Area rugosa present, represented by approximately six longitudinal ventral precloacal ridges (Fig. 2E,G). Preanal papillae: 10 and 11 papillae subventral and one pair lateral, latter situated in space between second and third (counted from cloaca) subventral pair. Postanal papillae: of six pairs, second pair lateral, remaining pairs subventral (Figs. 1F, 2C,F). Left spicule 315 long, length of shaft 174 , representing $55 \%$ of spicule length; distal tip of spicule somewhat expanded, provided with cuticular membrane. Right spicule 117 long, with dorsal barb at distal end (Fig. 1F). Length ratio of spicules 1 : 2.69. Tail 339 long.

Female (four gravid specimens): Length of body $12.02-15.50 \mathrm{~mm}$, maximum width 163-190. Length of vestibule including prostom 135-153; prostom 30 long, 21 wide. Muscular oesophagus 435-465 long, maximum width 36-39; glandular oesophagus 4.45-5.39 mm long, maximum width 93-120; length ratio of both parts of oesophagus $1: 10-12$. Entire oesophagus and vestibule representing $37-42 \%$ of body length. Nerve ring and excretory pore 189-207 and 341-448, respectively, from anterior extremity. In one specimen, deirids situated 108 and 117 from anterior end of body. Tail conical, 165-171 long, ending in sharp cuticular spike. Vulva postequatorial, 7.97-9.30 $\mathrm{mm}$ from posterior extremity, at $60-66 \%$ of body length. Vagina directed posteriorly from vulva. Fully developed eggs oval, smooth, containing larva (Fig. 1I); size 36-39 $\times 24(\mathrm{n}=5)$, thickness of shell 3 .

Host: Spotted steed, Hemibarbus maculatus Bleeker (Cyprinidae, Cypriniformes), total body length $29.5 \mathrm{~cm}$.

Site of infection: Intestine.

Locality: Ilistaya River (a tributary of Lake Khanka), Amur River basin, Primorsky Region (collected 19 June 2011).

Prevalence and intensity of infection: Eight nematode specimens found in the only fish examined.

Deposition of voucher specimens: Helminthological Collection of the Institute of Parasitology, BC AS CR (Cat. No. $\mathrm{N}-46)$.

Remarks. This nematode species is widely distributed over the entire Palaearctic Region, from western Europe to Russian Far East, China and Japan, where it occurs mainly in cyprinid fishes (Moravec 1975, 1994, Wang et al. 1979, Bauer 1987, Moravec and Nagasawa 1989). Moravec (1975) described and commented upon earlier descriptions of $R$. denudata and pointed out the morphological variation observed in worms from different host species and geographical areas.

Although some morphological features of Rhabdochona spp. and related forms (especially the structure of the cephalic end, shape of deirids, structure of the male caudal end) are difficult to observe by LM and it is highly desirable to use SEM for their detailed study (Moravec 2007a, 2010), to date the latter method has not been used for $R$. denudata. Consequently, this SEM study shows for 


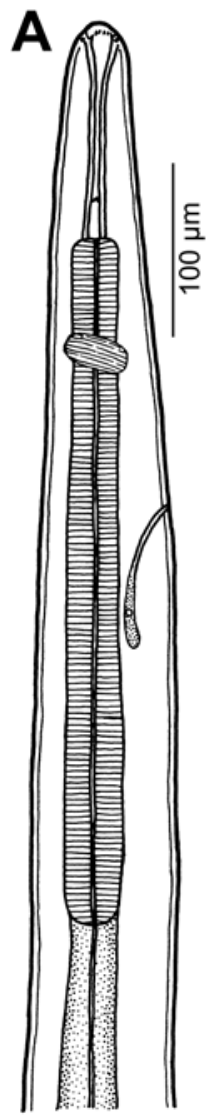

B
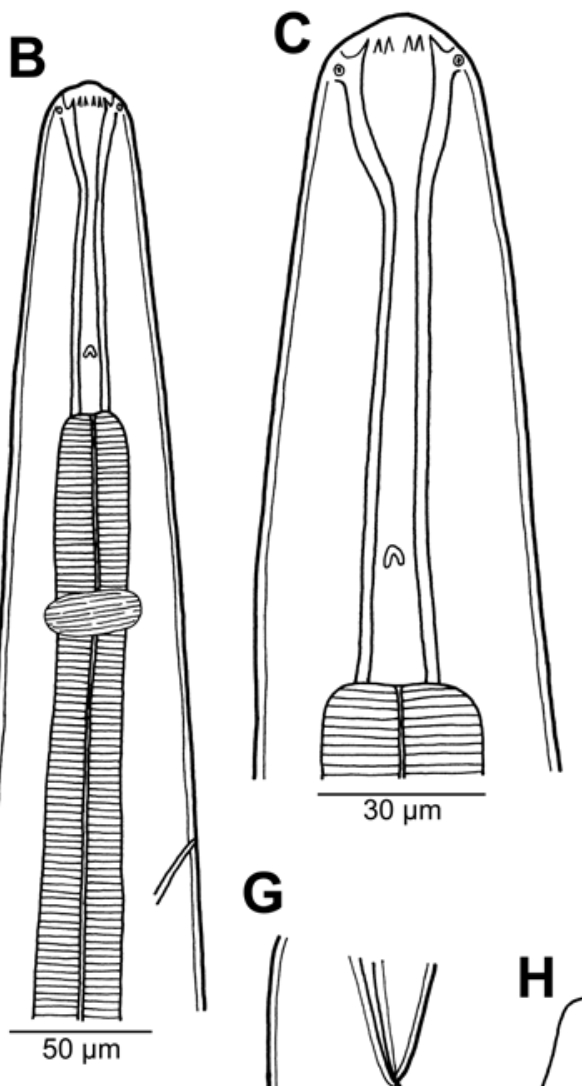

G

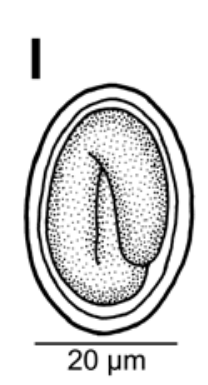

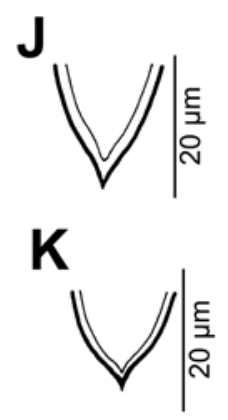

\section{$\mathbf{H}$}

D
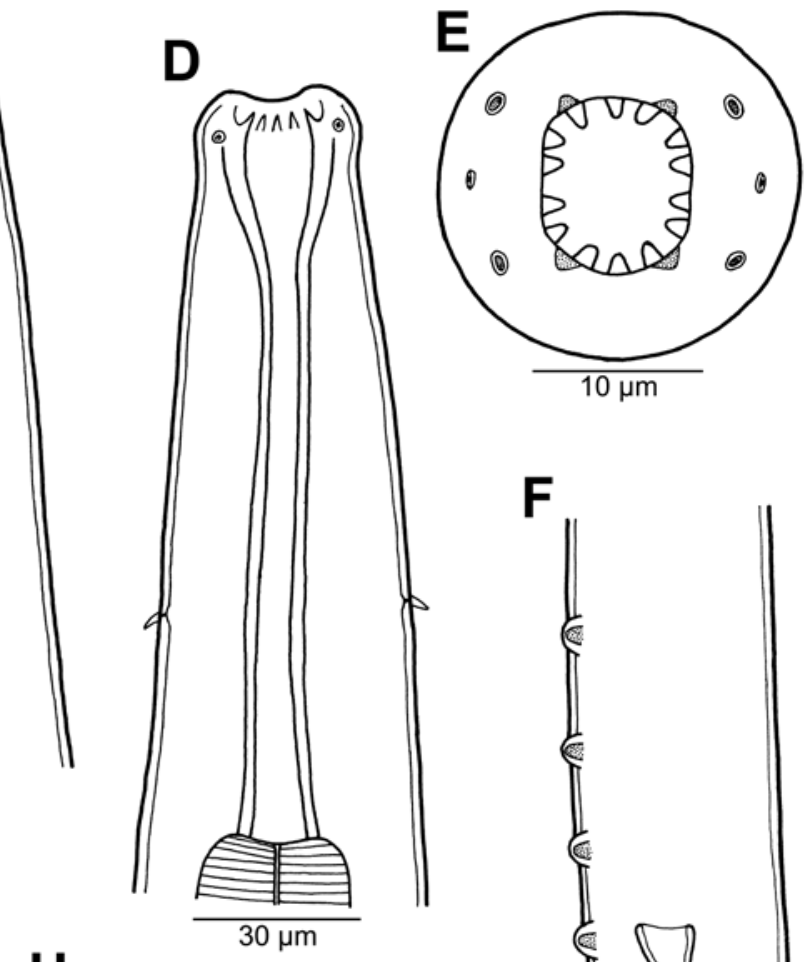

$\mathbf{F}$

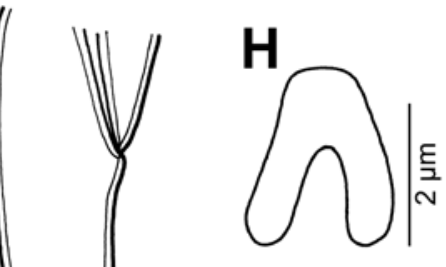

Fig. 1. Rhabdochona (Rhabdochona) denudata (Dujardin, 1845). A, B - anterior end, lateral views; C, D - region of vestibule (stoma), lateral and dorsoventral views; $\mathbf{E}$ - cephalic end, apical view; $\mathbf{F}$ - posterior end of male, lateral view; $\mathbf{G}$ - tail of female, lateral view; $\mathbf{H}$ - deirid; I - fully developed egg; J, K - tail tip of female and male, respectively.

the first time the presence of sublabia and the structure of male ventral cuticular ridges in this species, and confirms the number (14) and arrangement of anterior prostomal teeth, the shape of deirids, and the arrangement of male genital papillae. The LM and SEM examinations of the present Far-Eastern specimens show their agreement in all main morphological and biometrical features with the characteristics of $R$. denudata specimens in Europe (Moravec 1975). In contrast to data by Roytman and Trofimenko (1964) who reported a constant number (eight) of pairs of subventral preanal papillae in Far-Eastern specimens of $R$. denudata, observation of the only male speci- men of the present material, as well as data on nematodes reported as $R$. brevispicula (syn. of $R$. denudata) in Lake Khanka by Akhmerov (1965), indicate that the number of these papillae exhibits a certain degree of intraspecific variability. A considerable variation in the number of preanal papillae was also reported for $R$. denudata honshuensis Moravec et Nagasawa, 1989 in Japan (Moravec and Nagasawa 1989) and occurs also in most Rhabdochona spp. (see Moravec 2007a).

In contrast to $R$. denudata specimens from Central Europe (Moravec 1975), the prostom of the present FarEastern specimens seems to be slightly different (broader, 

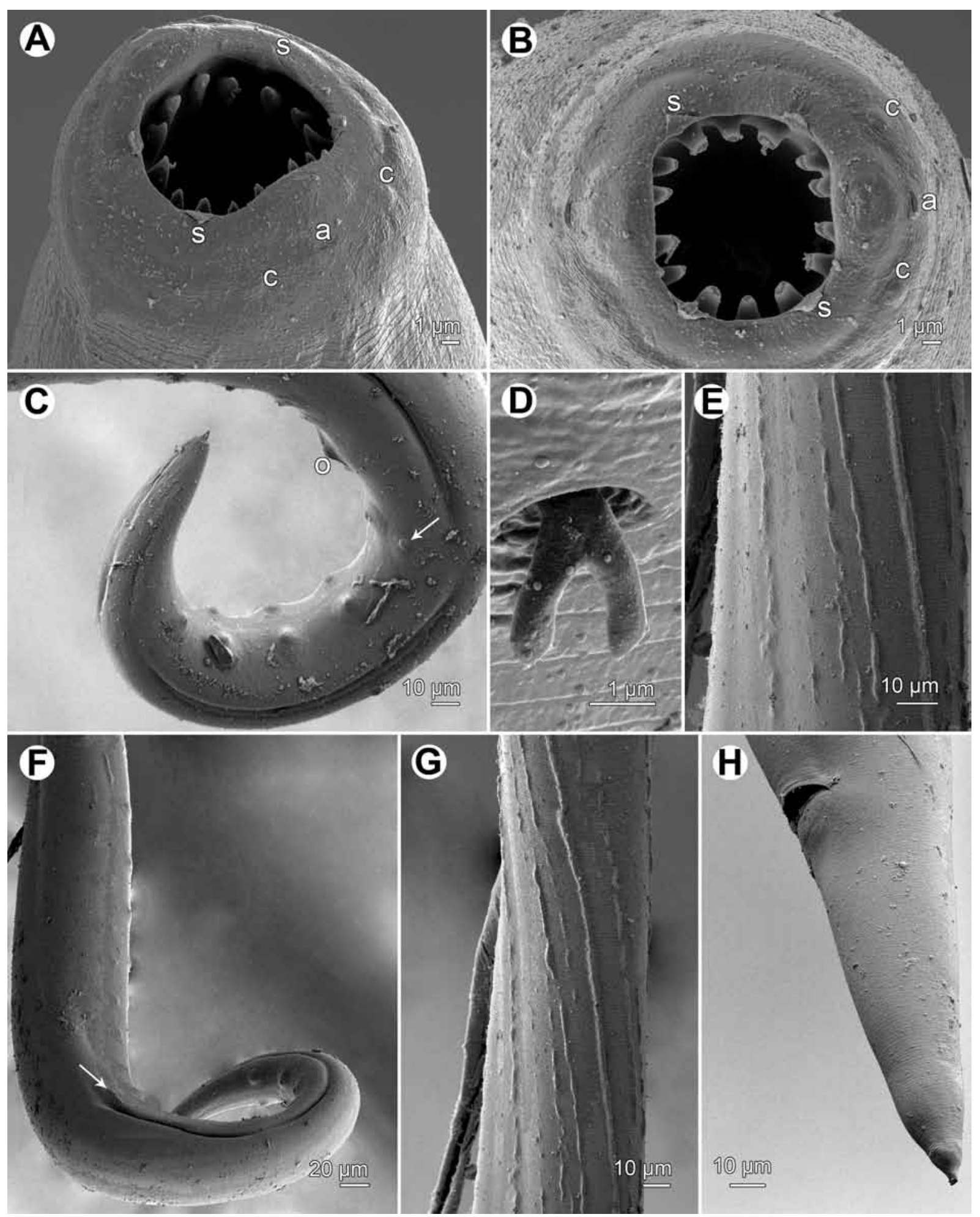

Fig. 2. Rhabdochona (Rhabdochona) denudata (Dujardin, 1845); SEM micrographs. A, B - cephalic end of female, sublateral and apical views; $\mathbf{C}$ - tail of male, sublateral view (arrow indicates lateral postanal papilla); D - deirid; $\mathbf{E}$ - ventral precloacal ridges; $\mathbf{F}$ - posterior end of male with distinct preanal papillae (arrow indicates lateral preanal papilla); $\mathbf{G}$ - longitudinal ventral precloacal ridges; $\mathbf{H}$ - tail of female, lateral view. Abbreviations: a - amphid; c - cephalic papilla; o - cloacal opening; s - sublabium.

with thicker walls), resembling that of $R$. longispicula or R. jiangxiensis Wang, Zhao, Wang et Zhang, 1979, parasites of cyprinids in the Far East of Russia and China, and
China and northern Vietnam, respectively (Moravec 1975, Moravec and Sey 1988), but these species differ from the present specimens in other features. It cannot be excluded 
that future studies will prove that the Far-Eastern specimens of $R$. denudata represent in fact a separate species.

In the Russian Far East, $R$. denudata has been reported from many fish hosts (mostly cyprinids, bagrids and salmonids) from the Amur River basin and the Primorsk Region (e.g., Dogel and Akhmerov 1959, Roytman 1963, Roytman and Trofimenko 1964, Belous 1965, Finogenova 1971), however, there were evident misidentifications in some cases. Moreover, Akhmerov (1965) described a new species, $R$. brevispicula, from Tachysurus braschnikowi (Berg) (Bagridae) from Lake Khanka and Finogenova (1967) R. crassa from Carassius gibelio (Bloch) (Cyprinidae) from the Budunda River (a tributary of the Zeya River), the Amur River basin; both of them were later synonymized with $R$. denudata by Moravec (1975), but $R$. crassa was considered a valid species by Ermolenko (1990, 1992). From cyprinids of the Amur River drainage system in Mongolia, $R$. denudata was recorded by Moravec and Ergens (1970), whereas Wang et al. (1979) reported $R$. denudata from the catfish Tachysurus fulvidraco (Richardson) in Central and South China.

The intermediate hosts of $R$. denudata in Europe and Japan were found to be ephemeropterans (Shtein 1959, Hirasawa and Urabe 2003, Moravec 2007b).

Rhabdochona (Rhabdochona) longispicula Belous in Roytman, 1963 Figs. 3, 4

Syn.: Rhabdochona longispicula Belous, 1965.

Description: Medium-sized nematodes with smooth cuticle. Oral aperture hexagonal, surrounded by four small submedian cephalic papillae and pair of amphids; four small submedian sublabia present (Figs. 3D, 4A,B). Prostom thick-walled, funnel-shaped, without basal teeth (Fig. 3A-C), lined internally with longitudinal ribs extending down to prostomal base; anterior ribs forming 14 small forwardly directed teeth (Figs. 3D, 4A,B). Vestibule straight, relatively long (Fig. 3A,B). Medium-sized deirids bifurcate, situated slightly posterior to middle of vestibule (Figs. 3A,B,G, 4D). Posterior part of glandular oesophagus occupies entire width of body. Tail of both sexes conical, with sharp cuticular spike at tip (Fig. 3J,K).

Male (one specimen): Length of body $10.42 \mathrm{~mm}$, maximum width 163 . Length of vestibule including prostom 159; prostom 24 long, 24 wide. Muscular oesophagus 345 long, maximum width 33; glandular oesophagus $3.78 \mathrm{~mm}$ long, maximum width 147 ; length ratio of both parts of oesophagus $1: 11$. Entire oesophagus and vestibule representing $41 \%$ of body length. Nerve ring and excretory pore 225 and 294, respectively, from anterior extremity. Deirids slightly asymmetrical, situated 93 and 96 from anterior end of body. Area rugosa present, formed by about ten ventral longitudinal precloacal cuticular ridges (Fig. 4E). Preanal papillae: seven pairs subventral and one pair lateral, latter situated in space between second and third (counted from cloaca) subventral pair (Figs. 3F,
4C); subventral preanal papillae surrounded by cuticular pores (Fig. 4F). Postanal papillae: of six pairs, second pair sublateral, remaining pairs subventral (Fig. 3F). Left spicule 786 long, length of shaft 375, representing 48\% of spicule length; distal tip of spicule funnel-shaped, provided with large cuticular membrane (Fig. 3E,F). Right spicule 153 long, with dorsal barb at distal end (Fig. 3F). Length ratio of spicules $1: 5.14$. Tail 612 long.

Female (one complete and one incomplete gravid specimens): Length of body $18.25 \mathrm{~mm}$, maximum width 354-381. Length of vestibulum including prostom 183-189; prostom 33-36 long, 27-30 wide. Muscular oesophagus 456-476 long, maximum width 39-45; glandular oesophagus 5.58-6.13 mm long, maximum width 218-245; length ratio of both parts of oesophagus $1: 12$ 13. Entire oesophagus and vestibule representing 34\% of body length. Nerve ring and excretory pore 270 and 396-423, respectively, from anterior extremity. Deirids slightly asymmetrical, situated 108 and 117 from anterior end of body in one specimen. Tail conical, 476 long, ending in sharp cuticular spike (Fig. $3 \mathrm{H}, \mathrm{K}$ ). Vulva postequatorial, $10.06-10.74 \mathrm{~mm}$ from posterior extremity, at 55\% of body length; vulval lips somewhat elevated. Vagina directed posteriorly from vulva. Fully developed eggs oval, smooth, containing larvae; size 36-39 × 21-24 $(n=5)$, thickness of shell 3 (Fig. 3I).

Host: Culter alburnus Basilewsky (Cyprinidae, Cypriniformes), total body length $27 \mathrm{~cm}$.

Site of infection: Intestine.

Locality: Ilistaya River (a tributary of Lake Khanka), Amur River basin, Primorsky Region (collected 23 June 2011).

Prevalence and intensity of infection: Four nematode specimens found in the only fish examined.

Deposition of voucher specimens: Helminthological Collection of the Institute of Parasitology, BC AS CR (Cat. No. N-979).

Remarks. The morphology and measurements of specimens of the present material correspond to R. longispicula as described by Belous $(1953,1965)$ and redescribed by Roytman (1963) and Moravec (1975). This species was first described in the thesis of Belous (1953), but the author published her results only in 1965. She (Belous 1965) reported $R$. longispicula from six fish hosts, Chanodichthys mongolicus (Basilewsky), Chanodichthys oxycephalus (Bleeker), Hemibarbus labeo (Pallas), Leuciscus waleckii (Dybowski), Rhynchocypris lagowskii (Dybowski) and Tribolodon brandtii (Dybowski) (all Cyprinidae), from Lake Khanka and its tributary Mel'gunovka (Mo) River, Razdolnaya (Suyfun) River, Ussuri River and its tributary Bol'shaya Ussurka (Iman) River (all Amur River basin), Primorsky Region. Belous's (1965) description of $R$. longispicula is inadequate, based on a single male and a single female, and the author did not mention the type host. Since all line drawings of this species accompanying the description were based on specimens from 

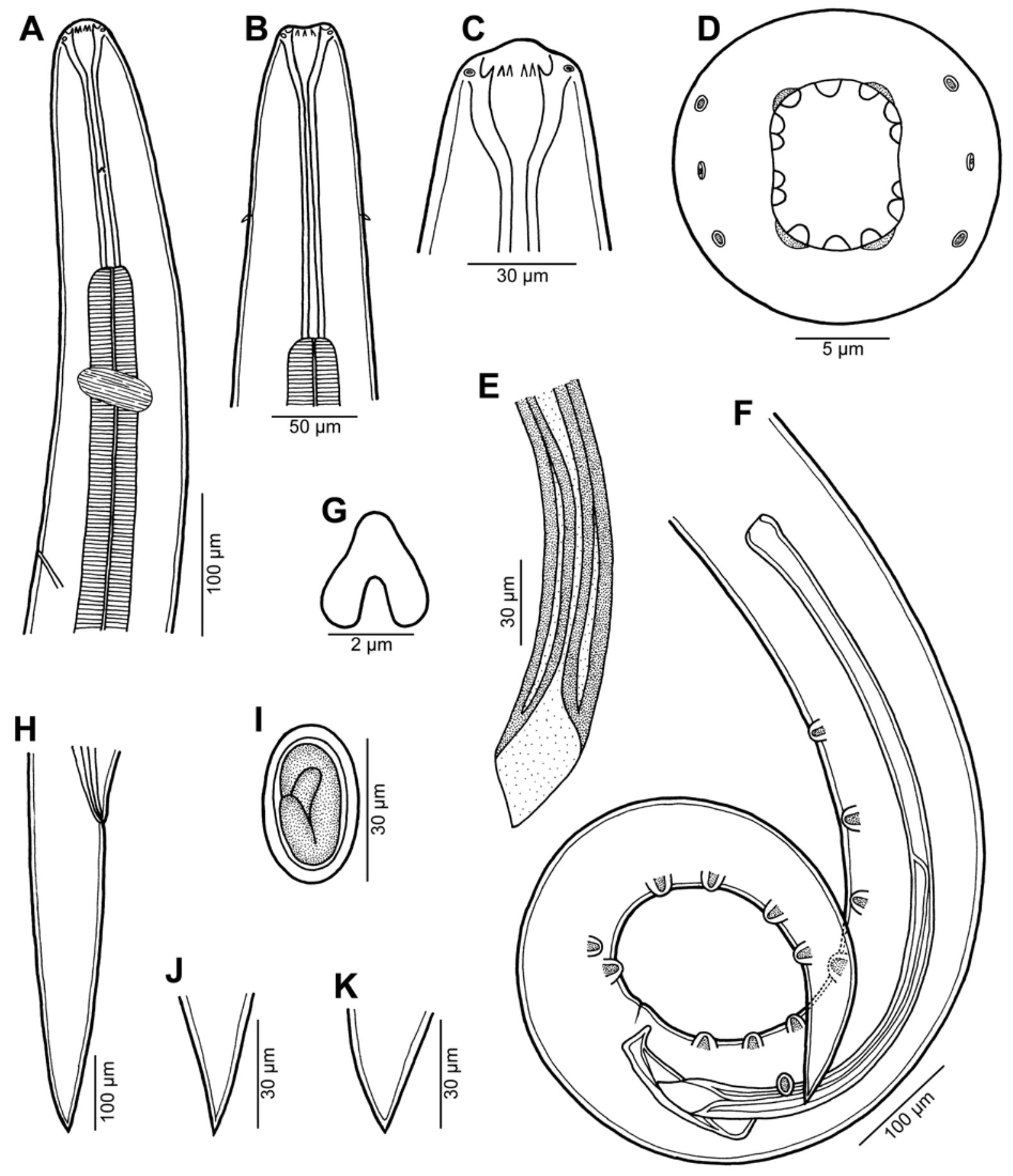

Fig. 3. Rhabdochona (Rhabdochona) longispicula Belous in Roytman, 1963. A, B - anterior end, lateral and dorsoventral views; C, D - cephalic end, lateral and apical views; $\mathbf{E}$ - distal end of left spicule, lateral view; $\mathbf{F}$ - posterior end of male, lateral view; $\mathbf{G}$ - deirid; $\mathbf{H}$ - tail of female, lateral view; $\mathbf{I}$ - fully developed egg; $\mathbf{J}, \mathbf{K}$ - tail tip of male and female, respectively.

C. mongolicus, it is possible to designate this fish as the type host.

Two years before the paper of Belous (1965) appeared, Roytman (1963), being familiar with the thesis of Belous (1953), published a redescription of this species under the invalid name Rhabdochona longispicula Belouss, 1952, where he also used the measurements of this species taken over from the thesis of Belous (1953). In fact, Roytman's (1963) paper contains the first published description of this species. However, he used the species name proposed by Belous and recognised her authority, and, moreover, he published the measurements of $R$. longispicula from her thesis (Belous 1953), which can be taken for the publication of the original description. Therefore, 

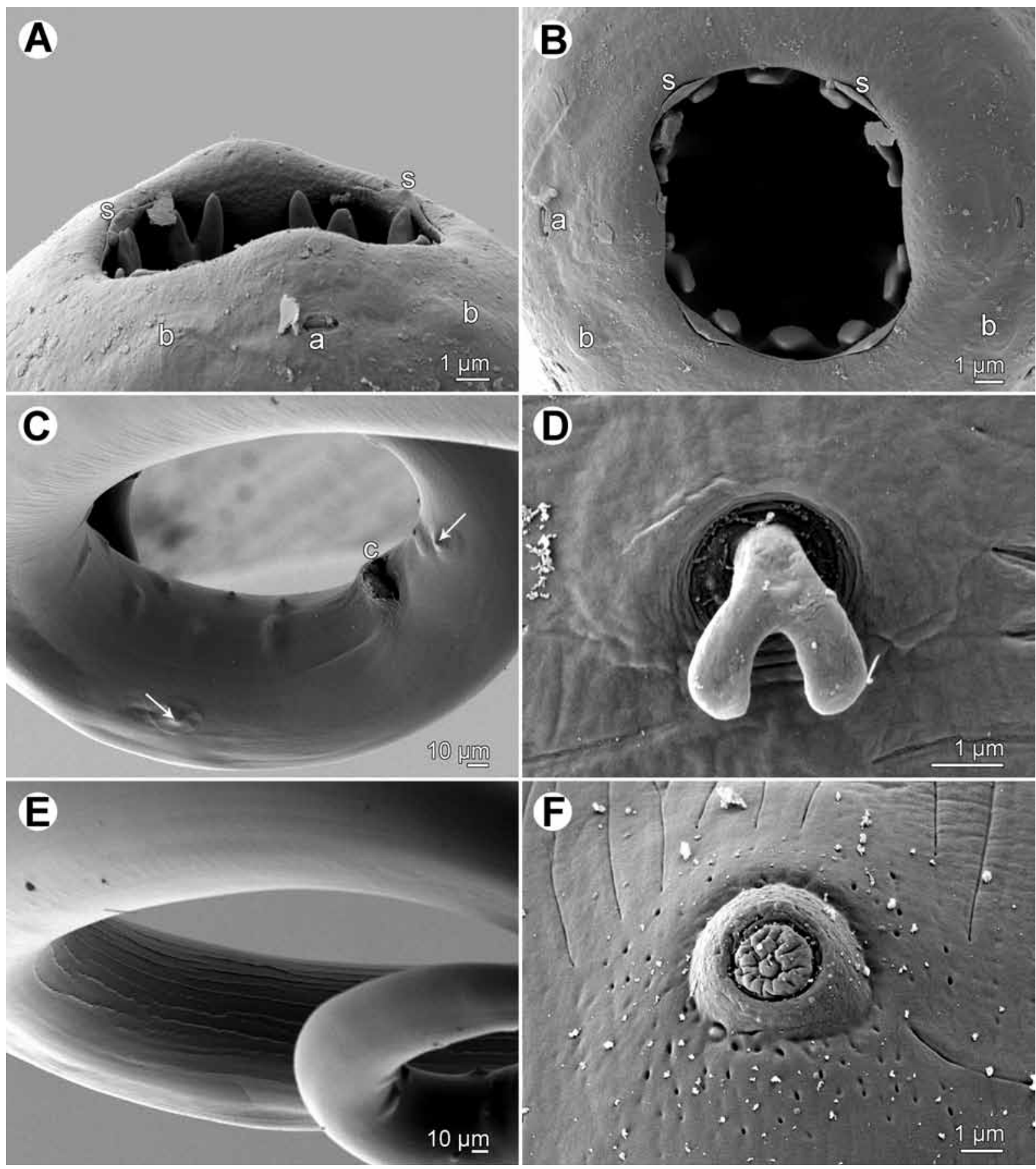

Fig. 4. Rhabdochona (Rhabdochona) longispicula Belous in Roytman, 1963; SEM micrographs. A, B - cephalic end, lateral and apical views; C - region of cloaca, sublateral view (arrows indicate lateral and sublateral papillae); D - deirid; $\mathbf{E}$ - distinct longitudinal cuticular ridges (area rugosa) on ventral precloacal region of male, ventral view; $\mathbf{F}$ - preanal papilla surrounded by cuticular pores. Abbreviations: a - amphid; b - cephalic papilla; c-cloacal aperture; $\mathrm{s}$ - sublabium.

in accordance with the International Code of Zoological Nomenclature (ICZN), the correct name of this species is R. longispicula Belous in Roytman, 1963. Previously, the authority of this species was incorrectly given as "Belouss, 1952", "Belouss, 1965" and "Belouss, 1955" by Skryabin et al. (1967), Moravec (1975) and Bauer (1987), respectively.
Roytman (1963) redescribed $R$. longispicula on the basis of specimens collected in Chanodichthys erythropterus (Basilewsky), Hemiculter leucisculus (Basilewsky), Leuciscus waleckii, Pseudaspius leptocephalus (Pallas) (all Cyprinidae) and Pelteobagrus ussuriensis (Dybowski) (Bagridae) from the Zeya River, a left tributary of the middle Amur River, Far East of Russia. For the first 
time, he determined the number (14) of anterior prostomal teeth and mentioned the presence of ventral precloacal ridges in this species. However, Roytman (1963) failed to observe lateral preanal papillae and deirids. Further, in contrast to the description provided by Belous (1953, 1965), he reported that the mature eggs of $R$. longispicula bear large lateral swellings. Moravec (1975) re-examined Roytman's specimens from $C$. erythropterus using light microscopy and observed no such swellings on eggs (later Dr. Roytman considered them to be artifacts - see Moravec 1975). Nevertheless, Roytman's (1963) erroneous and misleading illustration of the egg of $R$. longispicula bearing lateral swellings was used in the monograph of Bauer (1987). For the first time, Moravec (1975) reported the presence of small bifurcate deirids and one pair of lateral preanal papillae in this species.

The present SEM examination, carried out for $R$. longispicula for the first time, has confirmed some taxonomically important features, such as the shape of deirids, the number and arrangement of anterior prostomal teeth, the presence and situation of lateral preanal and postanal papillae, and the character of ventral precloacal ridges in the male. The four submedian cephalic structures reported by Roytman (1963) as internal cephalic papillae, occurring also in other congeneric species, were considered to be in fact sublabia by Moravec et al. (2010, 2012a,b,c) and Moravec and Yooyen (2011). R. longispicula is characterized mainly by the length of the left spicule and by the shape of its tip.

According to Moravec $(1975,2010)$ the main definitive hosts of $R$. longispicula seem to be fishes of the cyprinid subfamily Cultrinae (Chanodichthys erythropterus, C. dabryi, C. mongolicus, Culter alburnus, Hemiculter leucisculus) (see also Ermolenko and Butorina 1998). However, Belous (1953, 1965), Roytman (1963) and Ermolenko, Besprozvannykh and Nadtochiy (unpublished) also recorded this species from other cyprinids [Abbottina rivularis (Basilewsky), Hemibarbus labeo, H. maculatus, Leuciscus waleckii, Opsariichthys uncirostris (Temminck et Schlegel), Pseudaspius leptocephalus, Rhynchocypris czekanowskii (Dybowski), R. lagowskii, Romanogobio tenuicorpus (Mori), Tribolodon brandtii] and even from catfishes Pelteobagrus ussuriensis (Bagridae) and Silurus asotus Linnaeus (Siluridae) and from Lota lota (Linnaeus) (Lotidae, Gadiformes).

It is highly probable that some of these fishes are not true definitive hosts of $R$. longispicula but serve only as its paradefinitive or postcyclic hosts. However, a confusion with other morphologically similar Rhabdochona spp. cannot be excluded in some of these cases. For example, Finogenova (1971) reported $R$. denudata from 22 fish species belonging to Bagridae, Cottidae, Cyprinidae, Osmeridae and Salmonidae from the system of the Amur River, including some species previously reported by Belous $(1953,1965)$ and Roytman (1963) as hosts of $R$. longispicula. The description provided by Finogenova
(1971) (i.e. left spicule 615-714 long) and the drawings indicate that her material included $R$. longispicula (see Moravec 1975) and probably some other congeneric species. In addition to the above-mentioned records of $R$. longispicula from the Amur River basin in the Russian Far East, this species has also been reported from Chanodichthys erythropterus in Central and South China (Wang et al. 1979).

\section{Rhabdochona (Rhabdochona) spp.}

Gravid females but no males of these nematodes were collected in one of three Chanodichthys dabryi (Bleeker) examined from the Ilistaya River on 23 June 2011 (intensity five specimens) and in the only Rhynchocypris lagowskii (Dybowski) examined from the Komissarovka River on 27 June 2011 (intensity three specimens). Their morphology and measurements are very similar to those of the females of $R$. denudata or $R$. longispicula and it may well be that they belong to one or both of these species. However, without having the males, their species identification based on morphological and biometrical features is impossible. Considering species of the nominotypical subgenus Rhabdochona, Chanodichthys dabryi and Rhynchocypris lagowskii have been reported to harbour both $R$. denudata and $R$. longispicula (see Roytman 1963, Finogenova 1971, Ermolenko 1992).

The available specimens from these two host species are characterized by the prostom armed with 14 anterior teeth and no basal teeth, medium-sized bifurcate deirids and by smooth eggs without filaments or swellings. They have the following main measurements (three specimens from C. dabryi; measurements of three specimens from $R$. lagowskii in parentheses): Body length 9.44-13.51 (9.62-16.27) mm, width 204-272 (163-394). Vestibule including prostom 144-147 (132-144) long, size of prostom $27-30 \times 24(24 \times 18)$; length of muscular oesophagus 312-330 (345-360), of glandular oesophagus 2.98-4.05 $(2.92-3.97) \mathrm{mm}$. Nerve ring and excretory pore 204-213 (177-210) and 303-369 (261-330), respectively, from anterior extremity. Vulva situated at 5.66-7.52 (5.60-9.63) $\mathrm{mm}$ from anterior end of body. Tail 261-435 (201-490) long. Size of fully developed eggs 36-39 × 21-24 (36-39 $\times 21-24)$.

\section{Rhabdochona (Globochonoides) coronacauda} Belous, 1965

Figs. 5-7

Description: Small nematodes with finely transversely striated cuticle (Fig. 6D,F). Narrow lateral alae present, extending approximately from nerve ring level to about level of cloacal aperture in male and up to phasmids in female (Figs. 6C,E, 7C-E). Mouth oval, with four small submedian sublabia, surrounded by four submedian cephalic papillae and pair of lateral amphids (Figs. 5D, 6A,B). Prostom small, funnel-shaped, with distinct basal teeth (Fig. 5A-C). Six anterior teeth present: one dorsal, 

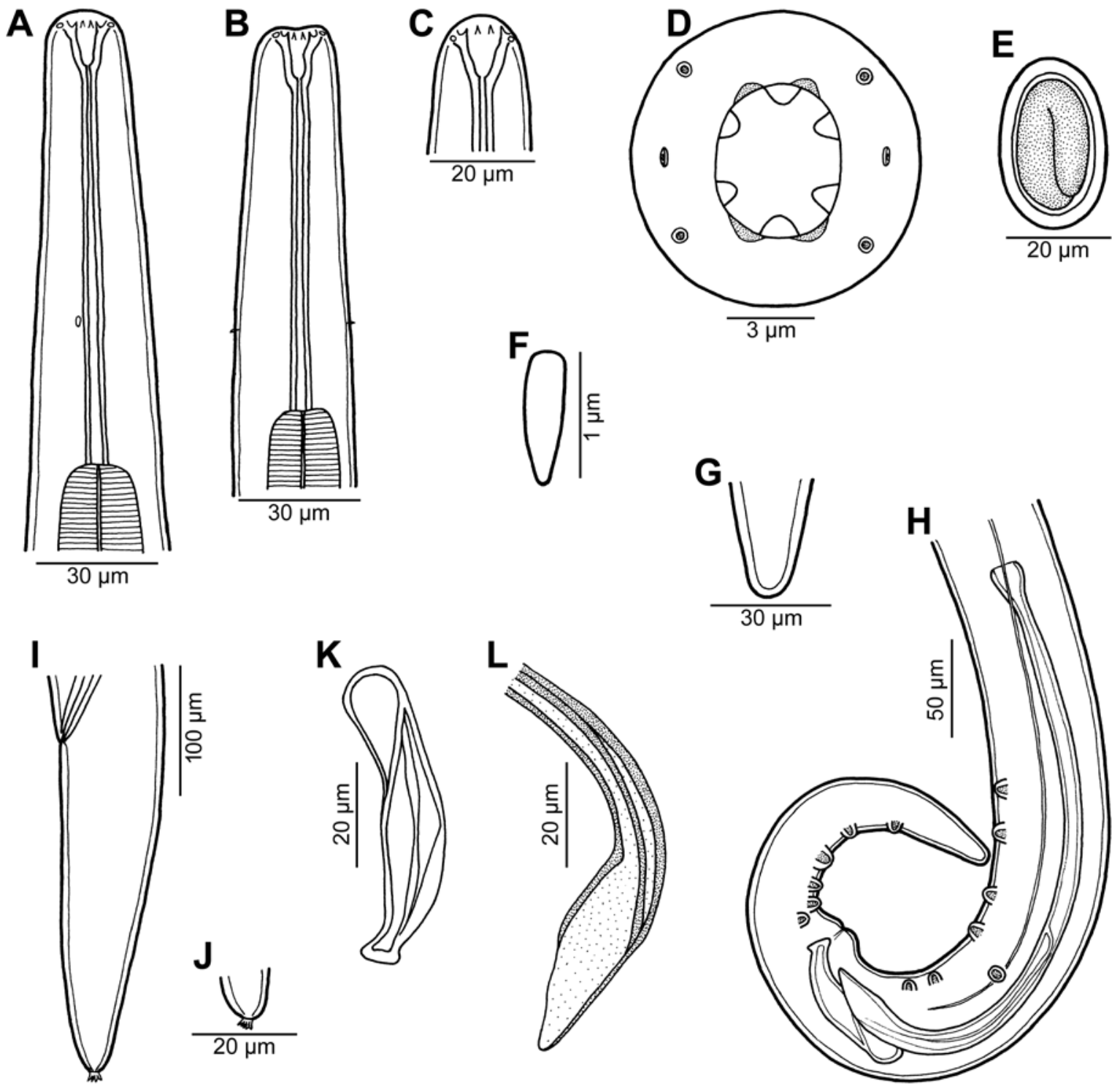

Fig. 5. Rhabdochona (Globochonoides) coronacauda Belous, 1965. A, B - anterior end of female, lateral and dorsoventral views; C, D - cephalic end, lateral and apical views; $\mathbf{E}$ - fully developed egg; $\mathbf{F}$ - deirid; $\mathbf{G}$ - tail tip of male; $\mathbf{H}$ - posterior end of male, lateral view; I - tail of female, lateral view; $\mathbf{J}$ - tail tip of female; $\mathbf{K}$ - right spicule, lateral view; $\mathbf{L}$ - distal end of left spicule, lateral view.

one ventral and four lateral (two on either side) (Figs. 5D, 6A,B). Vestibule relatively long. Minute deirids simple, located posterior to middle of vestibular length (Figs. 5A,B,F, 6D,G).

Male (one specimen): Length of body $3.59 \mathrm{~mm}$, maximum width 75. Anterior part of prostom of this specimen missing. Length of vestibule including prostom 99. Muscular oesophagus 156 long, 15 wide; glandular oesophagus 909 long, 45 wide; length ratio of both parts of oesophagus $1: 5.8$. Entire oesophagus and vestibule representing $32 \%$ of body length. Nerve ring and excretory pore 144 and 195, respectively, from anterior extremity. Preanal papillae: six pairs of subventral and one pair of lateral papillae; latter papillae located between second and third subventral pairs (counted from cloaca), interrupting lateral alae (Figs. 5H, 7C,D). Postanal papillae: five subventral pairs and one pair lateral located slightly anterior to first subventral pair; papillae of third subventral pair somewhat larger than those of remaining pairs (Figs. 5H, 7E). Ventral preanal cuticular ridges absent. Left spicule 372 long, length of its shaft 201, representing $54 \%$ of spicule length; distal tip of this spicule ventrally distended (Fig. 5H,L). Right spicule measuring 84, with barbed distal end (Fig. 5H,K). Length ratio of spicules $1: 4.43$. Tail conical, 177 long, with rounded tip (Figs. $5 \mathrm{G}, \mathrm{H}, 7 \mathrm{C}, \mathrm{D})$.

Female (three gravid specimens): Body $5.43-8.13 \mathrm{~mm}$, maximum width 114-171. Maximum width of lateral alae 
15. Prostom 15 long and 9-12 wide. Length of vestibule including prostom 126-141. Muscular oesophagus 186195 long, maximum width 18-24; glandular oesophagus 898-1 114 long, maximum width 57-81; length ratio of both parts of oesophagus $1: 4.8-6.0$. Entire oesophagus and vestibule representing $18-24 \%$ of body length. Nerve ring and excretory pore 186-201 and 261-276, respectively, from anterior extremity. Tail conical, 123-216 long, with truncated tip provided with small crown of minute tooth-like processes (Fig. 6F). Crown 3-4 long and 6-7 wide, consisting of 12 processes forming two groups of 8 and 4 (Figs. 5I,J, 7A,B). Vulva postequatorial, $2.92-4.30 \mathrm{~mm}$ from posterior extremity, at 53-55\% of body length. Vagina directed posteriorly from vulva. Fully developed eggs oval, smooth, larvated (Fig. 5E); size 36-39 $\times 21-24$, thickess of shell 3 .

Host: Culter alburnus Basilewsky (Cyprinidae, Cypriniformes), total body length $27 \mathrm{~cm}$.

Site of infection: Intestine.

Locality: Ilistaya River (a tributary of Lake Khanka), Amur River basin, Primorsky Region (collected 23 June 2011).

Prevalence and intensity: Four nematode specimens found in the only fish examined.

Deposition of voucher specimens: Helminthological Collection of the Institute of Parasitology, BC AS CR (Cat. No. N-41).

Remarks. The first description of this species was published by Belous (1965) under the name Rhabdochona coronacauda Belous, 1965, based on specimens collected from fishes in the Primorsky Region (Amur River basin), Russian Far East. Later, being not familiar with the Belous's (1965) paper, Skryabin et al. (1967) in their monograph published the description of this species under the name $R$. coronocauda Belouss, 1952, taken from the Belous's (1953) unpublished thesis. However, the latter name is unavailable according to the ICZN and cannot be considered a junior synonym. Although the original description of $R$. coronacauda provided by Belous (1965) is relatively good, some taxonomically important features, such as the detailed structure of the prostom, the number of anterior prostomal teeth or the presence of deirids and lateral alae, were omitted.

$R$. coronacauda was redescribed by Moravec et al. (1981) based on specimens from the cyprinid Opsariichthys uncirostris of Lake Biwa in Hoshu, Japan. These authors found for the first time, and in addition to some other features, the presence of conspicuous lateral alae extending along the body and, using LM, reported eight anterior teeth in the prostom. These data were previously included in the revisional work of Moravec (1975) who had established the monotypic subgenus Globochonoides Moravec, 1975 with type species $R$. coronacauda.

The redescription of this species by Moravec et al. (1981) was taken over in the Russian monograph of Bauer (1987). Later R. coronacauda was recorded from the Rus- sian Far East by Ermolenko (1990, 1992) and Ermolenko and Butorina (1998), and from Japan by Moravec and Nagasawa (1998). The latter authors mentioned that the nematodes reported as Rhabdochona chodukini Osmanov, 1957 by Chen (1973) from China undoubtedly belong to R. coronacauda (see also Moravec and Sey 1988). Apparently, Chen (1973) overlooked lateral alae in his nematodes, but in contrast to Moravec et al. (1981), he illustrated only six prostomal teeth.

The number of anterior prostomal teeth is one of the most stable and, therefore, a taxonomically very important morphological feature in Rhabdochona spp. (see Moravec 1972, 1975) which, along with some other characters, was used for the separation of subgenera in this genus (Moravec 1975, 2007a, 2010). However, it is usually difficult and very elaborate to establish the number of prostomal teeth in apical view in Rhabdochona spp. using LM and, consequently, such observations need not be always accurate. In contrast, SEM examination is quite reliable (Moravec 2007a), but this method has so far rarely been used for Rhabdochona spp. Accordingly, the actual number of prostomal teeth remains unknown for the great majority of the species in this genus or is given inaccurately.

The present SEM examination of $R$. coronacauda from the region where it was originally described shows clearly that this species possesses six anterior prostomal teeth; since the single dorsal and ventral teeth are larger than lateral ones in this species, now it is apparent that each of them was erroneously considered to be doubled by Moravec et al. (1981). Six anterior prostomal teeth are also present in the only other representative of the subgenus Globochonoides, $R$. (G.) squaliobarbi Moravec et Sey, 1988, a parasite of the cyprinid Squaliobarbus curriculus (Richardson) in Vietnam (Moravec and Sey 1988). The latter species differs from $R$. coronacauda mainly in the absence of a crown-like formation on the female tail tip and the substantially longer left spicule (462-561 $\mu \mathrm{m}$ vs. $285-372 \mu \mathrm{m})$.

Rhabdochona coronacauda has been reported from the following fish species: Carassius gibelio, Chanodichthys dabryi, C. erythropterus, C. mongolicus, C. oxycephalus, Culter alburnus, Cyprinus carpio carpio Linnaeus, C. carpio haematopterus Martens, Hemibarbus labeo, H. maculatus, Hemiculter leucisculus, Hypophthalmichthys molitrix (Valenciennes), Leuciscus waleckii, Opsariichthys uncirostris, Parabramis pekinensis (Basilewsky), Pseudorasbora parva (Temminck et Schlegel), Rhynchocypris lagowskii, Romanogobio tenuicorpus, Sarcocheilichthys czerskii (Berg), and Tribolodon brandtii (type host) (all Cyprinidae, Cypriniformes), but also in Cobitis lutheri Rendahl (Cobitidae), Liobagrus reinii Hingeldorf (Amblycipitidae), Silurus asotus (Siluridae), Salmo trutta fario Linnaeus (Salmonidae), Hypomesus olidus (Pallas) (Osmeridae), Esox reichertii Dybowski 


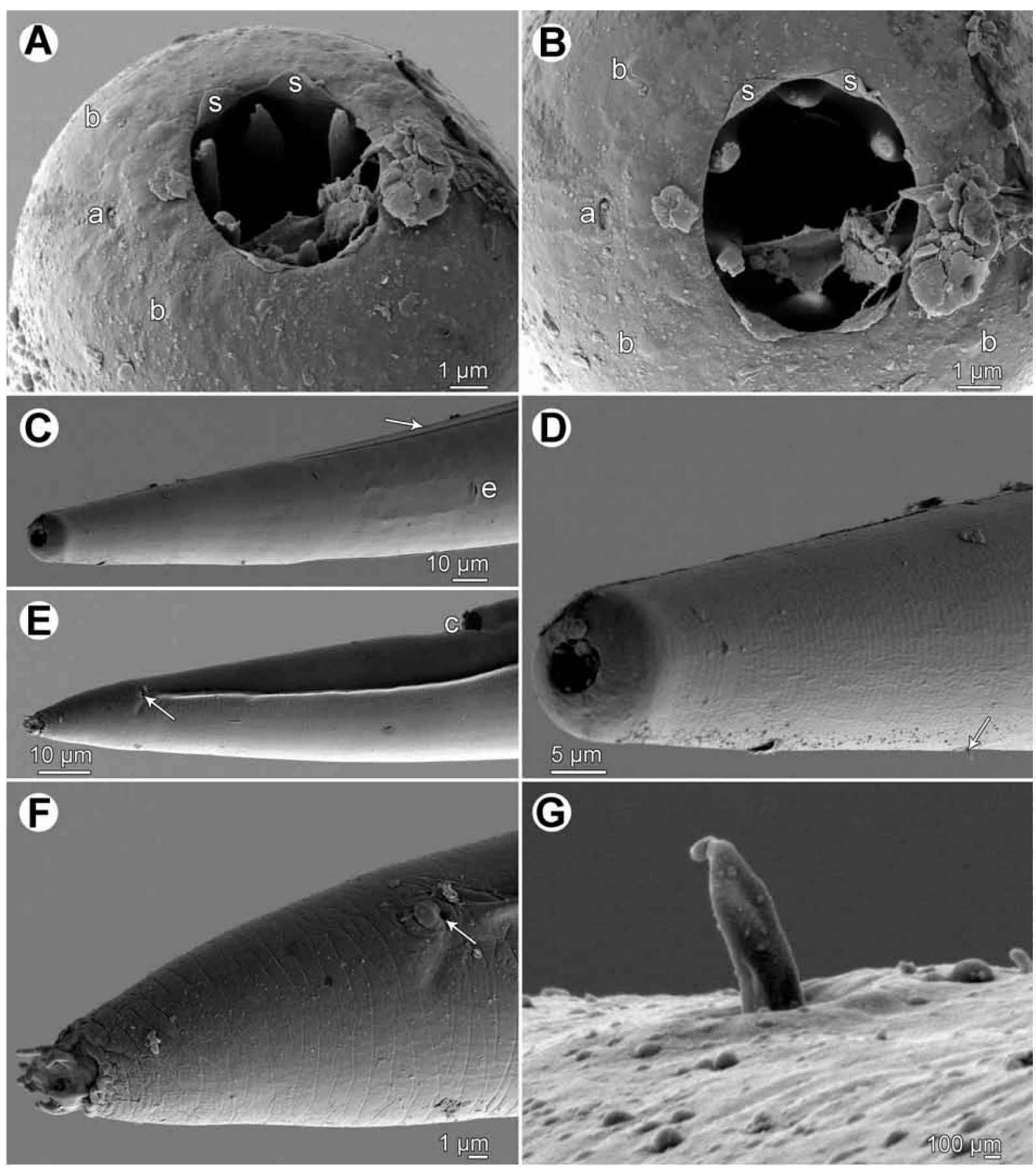

Fig. 6. Rhabdochona (Globochonoides) coronacauda Belous, 1965; SEM micrographs. A, B - cephalic end of female, dorsoventral and apical views; $\mathbf{C}$ - anterior end of body, ventral view (arrow indicates lateral ala); $\mathbf{D}$ - same, larger magnification (arrow indicates deirid); $\mathbf{E}$ - tail of female, lateral view (arrow indicates phasmid); $\mathbf{F}$ - posterior part of female tail, lateral view (arrow indicates phasmid); $\mathbf{G}$-deirid. Abbreviations: a - amphid; b - cephalic papilla; c - anal aperture; e - excretory pore; $\mathrm{s}$ - sublabium.

(Esocidae), Gymnogobius macrognathos (Bleeker) and Rhinogobius similis Gill (both Gobiidae), and Channa argus warpachowskii (Berg) (Channidae) (Belous 1965, Chen 1973, Moravec et al. 1981, Ermolenko 1990, 1992, Ermolenko and Butorina 1998, Moravec and Nagasawa 1998, Ermolenko, Besprozvannykh and Nadtochiy, unpublished). It appears that this parasite is largely associat- ed with cyprinids of the subfamily Cultrinae, whereas its findings in amblycipitid, channid, cobitid, esocid, gobiid, osmerid, salmonid and silurid fishes may represent accidental infections acquired by these fishes while feeding on infected true definitive fish hosts or ephemeropteran intermediate hosts harbouring $R$. coronacauda fourthstage larvae and possibly also juvenile adults. 


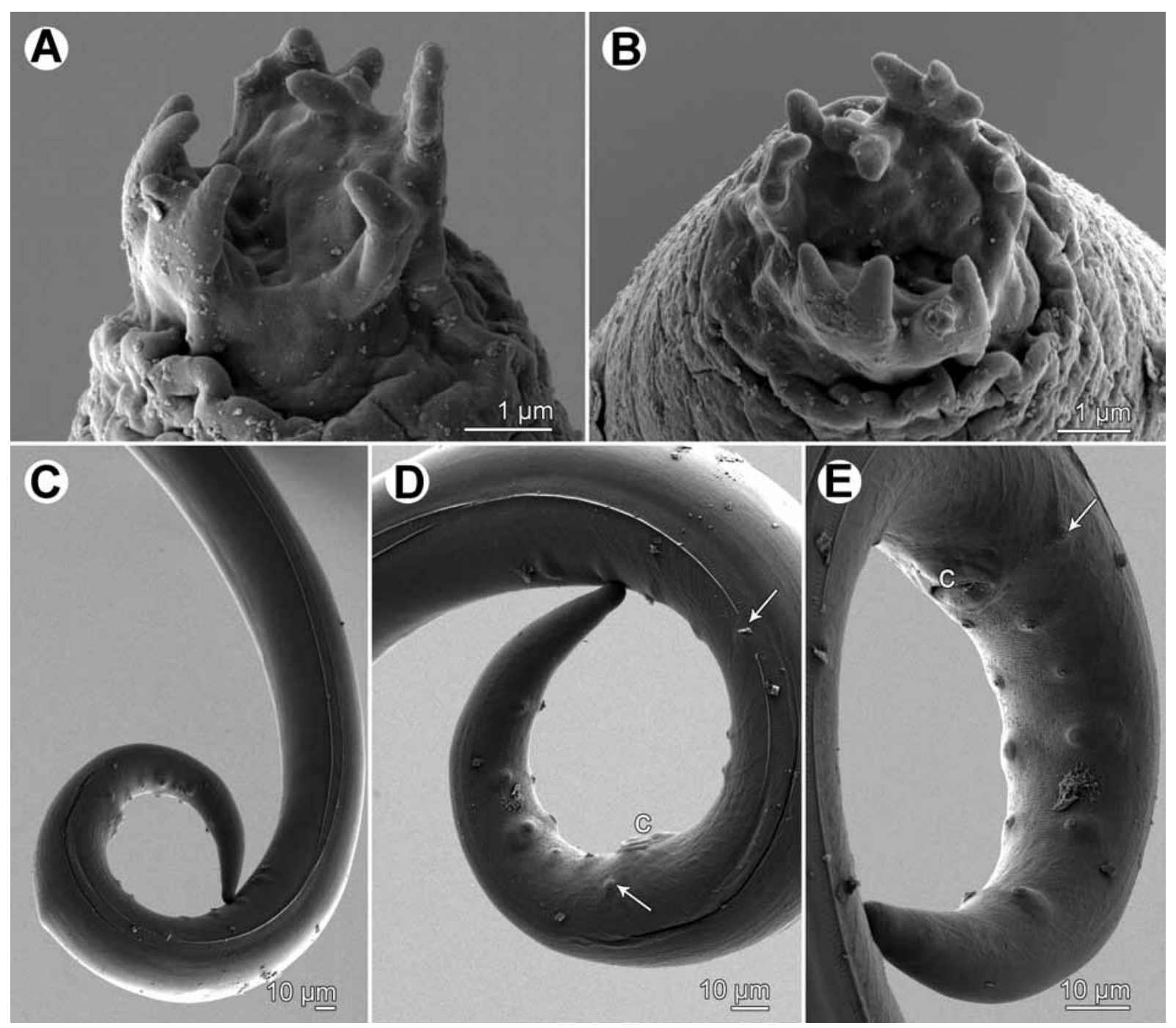

Fig. 7. Rhabdochona (Globochonoides) coronacauda Belous, 1965; SEM micrographs. A, B - tip of female tail with crown-like formation, subventral and apical views; $\mathbf{C}$ - posterior end of male with distinct lateral ala, lateral view; $\mathbf{D}$ - same, larger magnification (arrows indicate lateral papillae); $\mathbf{E}$ - tail of male, ventral view (arrow indicates lateral postanal papilla). Abbreviation: $\mathrm{c}$ - cloacal aperture.

The life cycle of $R$. coronacauda is unknown. Infective larvae of this nematode were found in the mayfly nymphs, Ephemera strigata (prevalence 19\%, mean intensity 3) and Ephemerella setigera (prevalence 1\%, mean intensity 2), of the Takami River, Honshu, Japan (Hirasawa and Urabe 2003).

This species is distributed in East Asia, where it has been recorded from fishes of the Russian Far East (Primorsky Region: Lake Khanka and its tributaries Mel'gunovka [Mo] and Komissarovka [Sintsukha] Rivers, Arsenyevka River [tributary of the Ussuri River], Razdolnaya [Suyfun] River, Barabashchevska [Mongugay] River) (Belous 1965) and Japan (Honshu: Lake Biwa, Sho River) (Moravec et al. 1981, Moravec and Nagasawa 1998). It was also recorded from China (misidentified as $R$. chodukini) by Chen (1973) (see Moravec and Sey 1988).

\section{DISCUSSION}

It has been mentioned above that five valid species of Rhabdochona have so far been reported from fishes of the Russian Far East: R. (R.) denudata, R. (R.) longispicula, $R$. (R.) oncorhynchi, $R$. (R.) zacconis and $R$. (G.) coronacauda. Of these, only $R$. oncorhynchi and $R$. zacconis have not yet been studied by SEM. Whereas $R$. denudata and $R$. oncorhynchi are Palaearctic species distributed both in Europe and Asia, R. longispicula and R. coronacauda occur only in East Asia (the former species in the Transitory Amur Region in Russia and China and the latter also in Japan) (Roytman 1962-1963, Chen 1973, Moravec 1975, Wang et al. 1979, Sterud et al. 1998). R. zacconis occurs in East Asia (Russian Far East and Japan) and western North America (British Columbia, Canada) (Moravec 1975, Arai and Mudry 1983). However, it can- 
not be excluded that additional species of Rhabdochona will be recorded from the territory of the Russian Far East.

Very interesting is the occurrence of $R$. (G.) coronacau$d a$, a representative of the subgenus Globochonoides, in the temperate zone of East Asia, because the only other species of this subgenus, $R$. (G.) squaliobarbi, occurs in the tropical region of Vietnam (Moravec and Sey 1988). Also the distribution of members of the closely related subgenus Globochona Moravec, 1972 is restricted to the tropical and subtropical regions of South Asia and Africa (Moravec 1975, 2010, Moravec and Yooyen 2011, Moravec et al. 2012a, Moravec and Kamchoo 2012). According to Moravec (2010) R. coronacauda can be considered an element of the Indian freshwater fauna, which was shifted to the north at the turn of Paleogene and Neogene (see Gusev 1969).

The morphology of $R$. coronacauda is remarkable not only because of the presence of lateral alae and some other features but also for the "crown-like formation" at the female tail tip. Numerous small cuticular outgrowths at the tail tip of the females or of both sexes are characteristic mainly of some Rhabdochona species of the subgenera Globochona and Globochonoides but also of one species (R. salgadoi Caspeta-Mandujano et Moravec, 2000 in Mexico) belonging to the nominotypical subgenus Rhabdochona (see Caspeta-Mandujano and Moravec 2000, Moravec 2010). Because of the small size of these caudal cuticular structures, it is almost impossible to study them in detail by LM. However, recent SEM studies of these caudal formations in a few species of Rhabdochona (see Caspeta-Mandujano and Moravec 2000, Moravec and Yooyen 2011, Moravec et al. 2012a, Moravec and Kamchoo 2012) have shown substantial interspecific differences in their structure.

Whereas only two ventral claw-shaped projections are present on the tail tip of $R$. $(G$.) thaiensis Moravec et Yooyen, 2011 and two lateral denticulate outgrowths, each bearing four horn-like projections, are found on that of R. (G.) kurdistanensis Moravec, Bilal et Abdullah, 2012 (see Moravec and Yooyen 2011, Moravec et al. 2012a), the female tail tip of $R$. (G.) coronacauda bears two broad lateral outgrowths, each with 4-8 digit-like projections surrounding a smooth central area demarcated by both outgrowths (present study). The female tail tip of $R$. (R.) salgadoi is provided with a small terminal rose-shaped outgrowth bearing numerous digit-like projections, whereas the male and female tail tips of $R$. (G.) rasborae Moravec et Kamchoo, 2012 have a somewhat more complex structure, where the terminal rose-shaped outgrowth bearing numerous digit-like projections is surrounded by a ring of thickened cuticle appearing as two small spines in lateral view (Moravec and Kamchoo 2012). Consequently, the detailed structure of such a caudal formation on the tail tip may serve as an important taxonomic feature in some Rhabdochona spp.

To date, the life cycle of any of the five Rhabdochona spp. recorded so far from the Russian Far East (see above) has not been studied experimentally. However, natural intermediate hosts of $R$. coronacauda, $R$. denudata honshuensis and $R$. oncorhynchi were found in Japan to be various ephemeropterans (Chloroterpes Eaton, Ephemera Linnaeus, Ephemerella Walsh, Potamanthus Pictet, Siphlonurus Eaton) in which Rhabdochona infective third- and fourth-stage larvae occur (Shimazu 1996, Hirasawa and Urabe 2003, Hirasawa and Yuma 2003). Experimental studies on the life cycles and larval morphogenesis of Far-Eastern species of Rhabdochona are highly needed.

Acknowledgements. We thank Tamara V. Volkova and Vladimir A. Chistyakov, both from the Instititute of Biology and Soil Science, FEB RAS, and Alain de Chambrier, Natural History Museum, Geneva for their invaluable assistance during the field work. Authors' thanks are also due to the staff of the Laboratory of Electron Microscopy, Institute of Parasitology, Biology Centre of the AS CR, České Budějovice for their technical assistance, and to Blanka Škoríková of the same Institute for help with illustrations. This study was partly supported by the Czech Science Foundation grant No. P505/12/G112 and by institutional support RVO:60077344.

\section{REFERENCES}

AkHmerov A.Kн. 1965: [Rhabdochona brevispicula nov. sp. a new nematode from fishes in Lake Khanka.] Trudy GELAN 15: 33-35. (In Russian.)

Arai H.P., Mudry D.R. 1983: Protozoan and metazoan parasites of fishes from the headwaters of the Parsnip and McGregor rivers, British Columbia: a study of possible parasite transfaunations. Can. J. Fish. Aquat. Sci. 40: 1676-1684.

Bauer O.N. (Ed.) 1987: [Key to parasites of the USSR freshwater fish fauna. Part 3. Parasitic metazoans 2.] Nauka, Leningrad, 583 pp. (In Russian.)

Belous E.V. 1953: [Parasitic worms of freshwater vertebrates of the Primorsky region.] PhD thesis of the All-Union K.I. Skryabin Institute of Helminthology (VIGIS), Moscow. (In Russian.)
Belous E.V. 1965: [Nematodes of freshwater fishes from the Primorsky region.] In: V.A. Leonov, Yu.L. Mamaev, P.G. Oshmarin (Eds.), Paraziticheskie chervi domashnikh i dikikh zhivotnykh. Raboty po gelmintologii k 40-letiyu nauchnoy i pedagogicheskoy deyatelnosti professora A.A. Soboleva, Vladivostok, pp. 48-65. (In Russian.)

Caspeta-Mandujano J.M., Moravec F. 2000: Two new intestinal nematodes of Profundulus labialis (Pisces, Cyprinodontidae) from fresh waters in Mexico. Acta Parasitol. 45: 332-339.

Chen C.L. (Ed.) 1973: [An illustrated guide to the fish diseases and causative pathogenic fauna and flora in the Hubei Province.] Academia Sinica Press, Beijing, 456 pp. (In Chinese.) 
Dogel V.A., Akhmerov A.Kh. 1959: [Nematodes of the Amur River.] Acta Hydrobiol. Sin. 3: 272-304. (In Chinese and Russian.)

Ermolenko A.V. 1990: [Causative agents of infectious diseases of freshwater fishes in Primorsk Region.] Biologo-pochvennyi institut AN SSSR, Vladivostok, 56 pp. (In Russian.)

ERmolenko A.V. 1992: [Parasites of fishes of freshwater reservoirs of the continental part of the Japan Sea basin.] Biologo-pochvennyi institut, DVO RAN, Vladivostok, 236 pp. (In Russian.)

Ermolenko A.V., Butorina T.E. 1998: [Parasite fauna of cyprinid fishes of the subfamily Cultrinae in the Lake Khanka basin.] Parazitologiya 32: 156-166. (In Russian with Engl. summary.)

Finogenova S.P. 1967: [New species of nematodes (Nematoda) from the Amur fishes.] Trudy Zool. Inst. AN SSSR 43: 93-98. (In Russian.)

FinOGENOVA S.P. 1971: [Round worms of fishes of the Amur River basin.] Trudy Zool. Inst. AN SSSR 25: 140-164. (In Russian.)

Froese R., Pauly D. (Eds.) 2012: FishBase. World Wide Web electronic publication, www.fishbase.org, version 05/2012.

Gusev A.V. 1969: [History of the fauna and attachment adaptations of the freshwater monogeneans of Eurasia and North America.] Parazitol. Sb. Zool. Inst. AN SSSR, Leningrad, 24: 106-127. (In Russian.)

Hirasawa R., URABE M. 2003: Ephemera strigata (Insecta: Ephemeroptera: Ephemeridae) is the intermediate host of the nematodes Rhabdochona denudata honshuensis and Rhabdochona coronacauda in Japan. J. Parasitol. 89: 617-620.

Hirasawa R., Yuma M. 2003: Ephemera strigata imagoes are the likely source of a parasitic nematode infection of fish. Folia Parasitol. 50: 313-314.

Moravec F. 1972: General characterization of the nematode genus Rhabdochona with a revision of the South American species. Acta Soc. Zool. Bohemoslov. 36: 29-46.

Moravec F. 1975: Reconstruction of the nematode genus Rhabdochona Railliet, 1916 with a review of the species parasitic in fishes of Europe and Asia. Studie ČSAV No. 8. Academia, Prague, 104 pp.

Moravec F. 1994: Parasitic Nematodes of Freshwater Fishes of Europe. Academia and Kluwer Academic Publishers, Prague and Dordrecht, Boston, London, 473 pp.

Moravec F. 2007a: Some aspects of the taxonomy and biology of adult spirurine nematodes parasitic in fishes: a review. Folia Parasitol. 54: 239-257.

Moravec F. 2007b: First experimental observations on the development of Rhabdochona denudata (Nematoda: Rhabdochonidae) in the intermediate host. Folia Parasitol. 54: 236-238.

Moravec F. 2010: Some aspects of the taxonomy, biology, possible evolution and biogeography of nematodes of the spirurine genus Rhabdochona Railliet, 1916 (Rhabdochonidae, Thelazioidea). Acta Parasitol. 55: 144-160.

Moravec F., Bilal S.J., Abdullah S.M.A. 2012a: Two species of Rhabdochona (Nematoda: Rhabdochonidae) from the cyprinid fish Luciobarbus kersin (Heckel) in northern Iraq, including R. (Globochona) kurdistanensis sp. n. Folia Parasitol. 59: $139-147$.

Moravec F., Ergens R. 1970: Nematodes from fishes and cyclostomes of Mongolia. Folia Parasitol. 17: 217-232.

Moravec F., Kamchoo K. 2012: Description of Rhabdochona (Globochona) rasborae sp. n. (Nematoda: Rhabdochonidae) from the freshwater cyprinid fish Rasbora paviana Tirant in southern Thailand. Folia Parasitol. 59: 209-215.

Moravec F., Margolis L., Boyce N.P. 1981: Some nematodes of the genus Rhabdochona (Spirurida) from fishes of Japan. Acta Soc. Zool. Bohemoslov. 45: 277-290.

Moravec F., Nagasawa K. 1989: Observations on some nematodes parasitic in Japanese freshwater fishes. Folia Parasitol. 36: 127-141.

Moravec F., Nagasawa K. 1998: Helminth parasites of the rare endemic catfish, Liobagrus reini, in Japan. Folia Parasitol. 45: 283-294.

Moravec F., Salgado-Maldonado G., González-Solís D., Caspeta-Mandujano J.M. 2012b: Host-parasite relationships of Rhabdochona kidderi Pearse, 1936 (Nematoda: Rhabdochonidae) in fishes of the Lacantún River in the Lacandon rain forest of Chiapas State, southern Mexico, with a key to Mexican species of Rhabdochona Railliet, 1916. Syst. Parasitol. 82: $1-12$.

Moravec F., Scholz T., Ash A., Kar P.K. 2010: New data on the morphology and taxonomy of three species of Rhabdochona (Nematoda: Rhabdochonidae) parasitizing fishes in India. Folia Parasitol. 57: 295-306.

Moravec F., Sey O. 1988: Nematodes of freshwater fishes from North Vietnam. Part 2. Thelazioidea, Physalopteroidea and Gnathostomatoidea. Acta Soc. Zool. Bohemoslov. 52: 176-191.

Moravec F., Sheeba S., Kumar A.B. 2012c: Rhabdochona (Rhabdochona) keralaensis sp. nov. (Rhabdochonidae) and some other nematodes in the Indian mottled eel Anguilla bengalensis bengalensis from India. Acta Parasitol. 57: 74-82.

Moravec F., Yooyen T. 2011: Two new species of Rhabdochona (Nematoda: Rhabdochonidae) from freshwater fishes in Thailand. Folia Parasitol. 58: 224-232.

RoYTMAN V.A. 1962-1963: [A zoogeographical characteristic of the helminth fauna of fishes of the Zeya River (the Amur River basin) and the ways of its formation.] Helminthologia 4: 404412. (In Russian with English, German and French summaries.)

Roytman V.A. 1963: [Nematodes of the Zeya River basin.] Trudy GELAN 13: 253-300. (In Russian.)

Roytman V.A., Trofimenko V.Ya. 1964: [Taxonomic importance of some morphological characters of Rhabdochona spp.] Helminthologia 5: 135-147. (In Russian with English and German summaries.)

Shimazu T. 1996: Mayfly larvae, Ephemera japonica, as natural intermediate hosts of salmonid nematodes, Sterliadochona ephemeridarum and Rhabdochona oncorhynchi, in Japan. Jpn. J. Parasitol. 45: 167-172.

Shtein G.A. 1959: [On the questions of the life history and living conditions of the nematode Rhabdochona denudata (Dujardin, 1845).] Doklady AN SSSR 127: 1320-1321. (In Russian.)

Skryabin K.I., Sobolev A.A., Ivashkin V.M. 1967: [Spirurata of Animals and Man and the Diseases Caused by Them.] Osnovy nematodologii 16. Nauka, Moscow, 624 pp. (In Russian.)

Sterud E., Thoen E., Haugland Ø. 1998: First record of Rhabdochona oncorhynchi (Nematoda: Rhabdochonidae) from brown trout in Europe. Bull. Eur. Assoc. Fish Pathol. 18: 206-208.

Wang P.-Q., Zhao Y.-R., Wang X.-Y., Zhang J.-V. 1979: Report on some nematodes from vertebrate animals in Central and South China. Fujian Shida Xuebao 2: 78-92. (In Chinese with English summary.) 